\title{
International perspectives on innovation: introduction
}

\author{
Nicholas S. Vonortas ${ }^{1,2,3}{ }_{(D}$
}

Published online: 7 March 2017

(C) Springer Science+Business Media New York 2017

JEL Classification L2 $\cdot \mathrm{O} 3$

The set of issues one must deal with across the spectrum of science, technology and innovation is quite immense. Idea exploration, exploitation and commercialization touch upon and are affected by a myriad different factors of technical and socio-economic nature (Leyden and Link 2015; OECD 2015; Vonortas et al. 2014). The concept of the policy mix defined as " ... the combined set of interacting policy instruments of a country addressing R\&D and innovation" (De Heide 2011) has been offered as one way of addressing this complexity (Rogge and Reichardt 2016). Figure 1 below provides an illustration.

In Fig. 1, the core domains of $R \& D$ and of Innovation are surrounded and directly affected by a broad set of issue/policy areas (dark grey), a much broader set of issues in lighter grey, and by a set of external (contextual) environments defined by macroeconomic environments, financial and fiscal structures, stakeholder interests, and international obligations. Given this dependence on context, the conspicuous void on information from an international perspective, especially a comparative international perspective, looks peculiar.

The papers in this collection are distributed across both the R\&D and Innovation domains as well as several policy areas: they deal with R\&D but also with innovation; they deal with inter-organizational interaction such as in university-industry collaboration; they deal with small, entrepreneurial companies; they deal with regional issues; they deal with the development/acquisition of private sector capabilities; they use novel large databases; and they deal with countries that have not received wide attention in Western academic

Nicholas S. Vonortas

vonortas@gwu.edu

1 Center for International Science and Technology Policy, Department of Economics, The George Washington University, Washington, DC, USA

2 University of Campinas, Campinas, Brazil

3 National Research University Higher School of Economics, Moscow, Russian Federation 


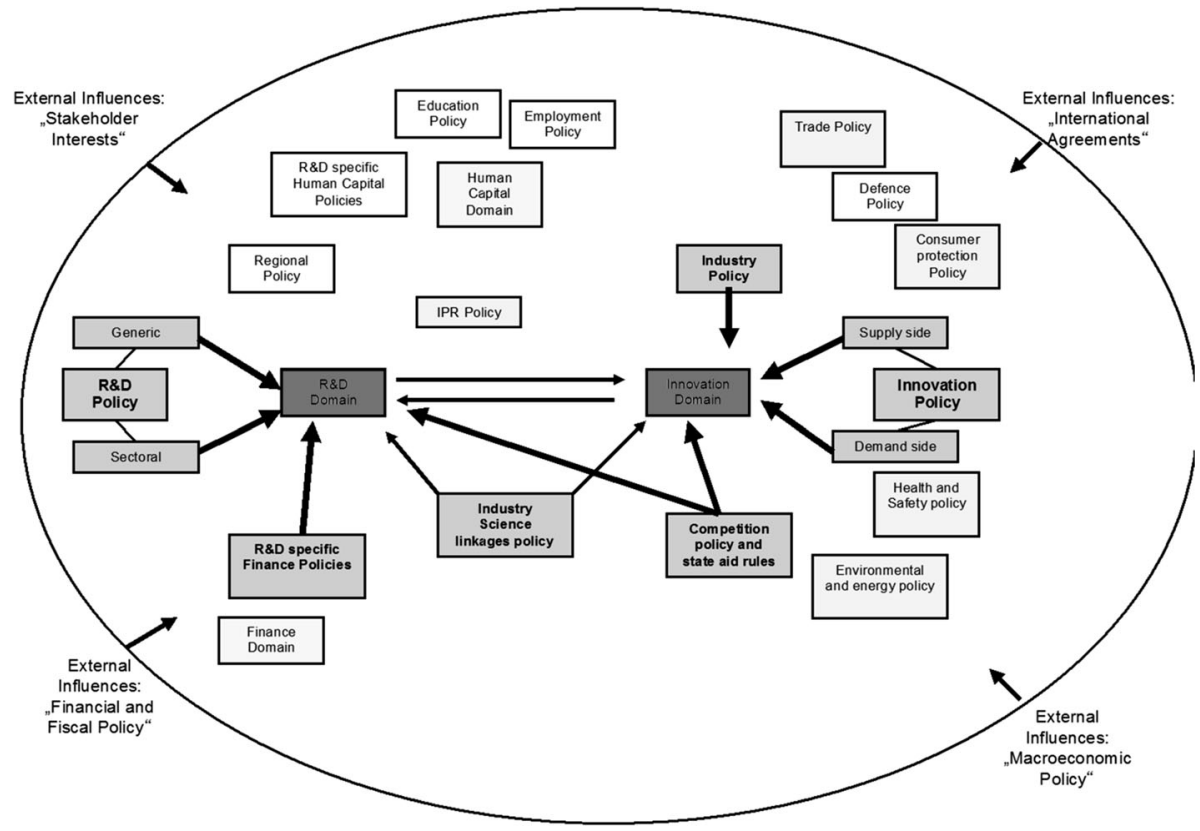

Fig. 1 Policy mix. Source: adapted from Nauwelaers et al. (2009)

literature. They were first presented in the 2016 annual conference of the Technology Transfer Society hosted by Arizona State University.

The paper by Fischer, Schaeffer, Vonortas and Queiroz deals with the role of universities as generators and disseminators of new knowledge through linkages with industry. Specifically, the paper looks at the generation of new knowledge-intensive ventures as a byproduct of the interaction between firms and academia through collaborative research. It thus addresses the question of whether university-industry research interactions generate substantial learning effects to transform academic institutions into more active generators of knowledge-intensive entrepreneurship (KIE). The paper uses the context of a knowledge-intensive region (State of São Paulo) in a developing country (Brazil). It puts together data on grants from the PIPE program (similar to the US SBIR program) to build a proxy of university entrepreneurship and data on university-industry research collaboration from the Brazilian National Council for Scientific and Technological Development (CNPq) Research Group Directory Census covering many universities and research institutes within the State of São Paulo. The authors are able to weigh the quality of research collaboration in terms of density, width, and depth, thus providing a more refined picture than available in the extant literature. They find that it is the quality, rather than quantity, of university-industry interaction that contributes to academic entrepreneurship.

The paper by Silva, Furtado and Vonortas takes the discussion of university-industry research cooperation at the sectoral level. Its contribution is the examination of traditional hypotheses on university-industry linkages across the industrial spectrum in a developing country setting. The paper uses data from Brazil's Innovation Survey (PINTEC) to develop explanatory factors of university-industry research collaboration including firm characteristics (size, intramural $R \& D$, extramural $R \& D$, product and process innovativeness), market characteristics (economic risk, innovation cost) and government funding. It is found 
that, when the most R\&D-intensive sectors are excluded, the main determinants of university-industry collaboration are firm size, extramural R\&D, and product innovativeness. Extramural R\&D appears as the most important determinant among the three and seems to occur at the expense of intramural R\&D, suggesting a substitution effect. When the R\&Dintensive sectors are included in the analysis, the main predictors are firm size, intramural R\&D and government funding, providing support to an argument of absorptive capacity: firms will collaborate with universities if they feel capable to absorb the resulting knowledge.

The paper by SooGeun, Yoon and Kim takes us to Korea to examine the relationship between the innovation activities of a firm and its expected future performance. The authors analyze the dynamic association between innovation activities, firm growth, and $\mathrm{R} \& \mathrm{D}$ investment growth in the longitudinal setting of a dynamic co-evolving system. They analyze the mediating role of firm growth in the relationship between innovation activities and $R \& D$ investment growth in a set of almost six hundred South Korean small and medium sized enterprises (SMEs). The study uses quantile regression analysis with longitudinal data for 17 years on these companies. It is found that the innovation activities of SMEs at a specific time period influence sales growth (in contrast to value growth) of highgrowth firms and high-tech sectors the next time period more positively than that of lowgrowth firms and low-tech sectors. Furthermore, SME sales growth have a significantly positive effect on subsequent R\&D investment growth. Theoretical and managerial implications are also discussed.

The paper by Breznitz, Clayton, Defazio and Isset deals with the effect of universitybased entrepreneurial support organization efforts to create a context and opportunities for interaction among start-up companies. The objective is the development of networks facilitating access to knowledge and resources, thus increasing the chances of start-up success. The paper develops the case of one university-based support organization in the United States using a large sample of participating firms with different levels of membership-support. This empirical context allows the authors to identify the dimensions that enhance the firm's ability to establish ties with other members. Geographical proximity, service support including shared space, and a larger community of member and graduate firms to which network ties may be formed increases the chance of connecting with other past or current member firms. The findings are in agreement with our current understanding of the importance of university incubators as a source of social capital. Universities provide a physical meeting space, but they are also an anchor organization that facilitates ties by managing their pool of historical network of member firms.

Finally, the paper by Zaichenko addresses the question of science-intensive technology transfer by stand-alone research and technology organizations (RTOs) in the Russian Federation. The examined RTOs' mission is to combine intramural R\&D and technology extension for industrial application. The paper is based on a unique large database of Russian organizations that allows to relate RTO science-based activity to technology transfer performance, on the one hand, and the contribution of $R \& D$ personnel sourced from universities to research output, on the other. The large sample allows differentiation among RTOs with various ownership structures and technology transfer orientation. The results indicate a positive relationship between RTO scientific publication and technology transfer activity. Science-based outputs are contributed mostly by researchers coming to RTOs from academia and especially by doctoral candidates. The results are important for countries where large numbers of RTOs play an important intermediary role between university science and industry-led technological innovation. 
The rich snapshots provided by this collection of papers should be viewed in light of the multi-faceted policy systems and variegated sets of contextual environments in place across the four countries represented herein.

\section{References}

De Heide, M. J. L. (2011). R\&D, innovation and the policy mix. Tinbergen Institute Research series, no. 508.

Leyden, D. P., \& Link, A. N. (2015). Public sector entrepreneurship. Oxford: Oxford University Press.

Nauwelaers, C., Boekholk, P., Mostert, B., Cunningham, P., Guy, K., Hofer, R., et al. (2009). Policy mixes for R\&D in Europe. European Commission, Directorate General for Research.

Organization for Economic Cooperation and Development. (2015). System innovation: A synthesis report. Paris: OECD.

Rogge, K., \& Reichardt, K. (2016). Policy mixes for sustainability transitions: An extended concept and framework for analysis. Research Policy, 45, 1620-1635.

Vonortas, N. S., Rouge, P., \& Aridi, A. (2014). Innovation policy: A practical introduction. New York: Springer. 